\title{
RESEARCH
}

Open Access

\section{The relationship of HLA-G 14-bp insertion/ deletion genetic polymorphism to the risk of multiple sclerosis and its clinical phenotypes}

Wafaa M. Farghaly ${ }^{1}$, Heba M. Saad Eldien ${ }^{2,3}$, Mohammed A. Sayed ${ }^{4}$, Hassan M. Elnady ${ }^{4}$, Ashraf Khodeary ${ }^{5}$, Abdelhady R. Abdel-Gawad ${ }^{5}$, Hamdy N. El-Tallawy ${ }^{1}$, Mohammed G. Abdellatif ${ }^{4^{*}}$ (1) and Hazem K. Alhewaig ${ }^{4}$

\begin{abstract}
Background: Human leukocyte antigen (HLA)-G molecule has been suggested to have a potential immunomodulatory role in multiple sclerosis (MS). Genetic variant sites of HLA-G molecule have been reported to be associated with autoimmune diseases. Identifying the genetic risk factors of MS may help in preventive strategies and anticipating disease progression. The aim of this work was to investigate the effect of HLA-G 14-base-pair insertion/deletion (14-bp INS/DEL) genetic polymorphism on MS risk and clinical characteristics and to observe the clinical characteristics of the MS patients' group. The study included 48 MS patients and 50 cross-matched healthy controls, who were recruited from Sohag and Assiut university hospitals. Genetic testing (14-bp Ins/Del gene polymorphism) using polymerase chain reaction (PCR) was performed for patients and control groups. All patients had a detailed clinical assessment and have undergone measurement of disability using the Expanded Disability Status Scale (EDSS).

Results: No statistically significant difference was found between MS patients and healthy controls (HC) in genotypic and allelic frequencies of HLA-G 14-bp INS/DEL polymorphism ( $P=0.305$ ). No significant association was found between HLA-G 14-bp INS/DEL polymorphism genotypes and clinical characteristics or degree of disability of MS patients. The most frequent presenting symptoms of MS were motor symptoms. Fatigue was the most reported symptom along the course of MS disease.

Conclusion: Although it has been long known that HLA-G represents an important MS susceptibility locus, in this study, no significant relation could be detected between the 14-bp INS/DEL polymorphism genotype and MS susceptibility. MS risk susceptibility may be not linked to a single allele but may depend on the combination of different polymorphic genetic sites. In this study, the lack of genetic susceptibility may be attributed to ethnic factor.
\end{abstract}

Keywords: HLA-G, Multiple sclerosis, Polymorphism, 14-bp insertion/deletion

\footnotetext{
* Correspondence: docadam20019@gmail.com

${ }^{4}$ Department of Neurology, Faculty of Medicine, Sohag University, Sohag,

Egypt

Full list of author information is available at the end of the article
}

(-) The Author(s). 2021 Open Access This article is licensed under a Creative Commons Attribution 4.0 International License, which permits use, sharing, adaptation, distribution and reproduction in any medium or format, as long as you give appropriate credit to the original author(s) and the source, provide a link to the Creative Commons licence, and indicate if changes were made. The images or other third party material in this article are included in the article's Creative Commons licence, unless indicated otherwise in a credit line to the material. If material is not included in the article's Creative Commons licence and your intended use is not permitted by statutory regulation or exceeds the permitted use, you will need to obtain permission directly from the copyright holder. To view a copy of this licence, visit http://creativecommons.org/licenses/by/4.0/. 


\section{Background}

Multiple sclerosis (MS) is an autoimmune demyelinating disease of the central nervous system (CNS) with multifactorial interacting environmental and genetic factors [1]. The Middle East and North Africa are present in a moderate risk zone for MS based on the 2013 MS Atlas [2].

Whole genome studies concluded that the genetic site of human leucocyte antigen-G (HLA-G) represents an important MS susceptibility locus [3]. HLA-G is a nonclassical major histocompatibility complex (MHC) molecule where it is present at chromosome 6. It has important immunomodulatory and tolerogenic functions [4].

$\mathrm{MHC}$ genetic site plays a basic role in MS risk through the rs4959039 single nucleotide polymorphism (SNP) in the $3^{\prime}$ untranslated region (3'UTR) of the HLA-G gene [5].

Variable genetic polymorphisms at the 3'UTR site have been proposed to be involved including insertion/ deletion (INS/DEL) of 14 base pairs $(14 \mathrm{bp})$ polymorphism (rs1704) [6]. The 14-bp insertion/deletion (INS/ DEL) polymorphism (rs66554220) present at the position +2960 in the exon 8 of the 3'UTR [7]. 14-bp insertion (INS) presence affects messenger ribonucleic acid (mRNA) splicing which contributes to lowering in HLA$G$ protein output, whereas the deletion allele (DEL) stabilizes the mRNA with higher HLA-G expression [8].

MS has markedly variable clinical characteristics and prognosis and some have early severe disability but others are still ambulatory and functioning for many years [9].

The aim of the current study is to investigate the relationship of genetic polymorphism of HLA-G 14-bp ins/ del with MS risk and clinical characteristics in Egyptian MS patients.

\section{Methods \\ Subjects}

This case-control study included 52 patients who were recruited from inpatient neurology departments and outpatient neurology clinics and 50 healthy controls in a multicenter study. Four patients were excluded from the study. They were proved to have alternative diagnosis as systemic lupus erythematosus (one patient), Behcet disease (one patient), and other neurologic disorders (two patients with transverse myelitis).

\section{Inclusion criteria}

Forty-eight MS patients diagnosed with clinically definite MS (CDMS) were selected based on Revised McDonald's criteria (2017) [10]. Fifty age and sex cross-matched healthy individuals with no past medical history of autoimmune diseases or other neurologic diseases were included as the control group.

\section{Ethical consideration}

The study protocol was approved by the Ethics committee of the Faculty of Medicine in November 2016. Written informed consent was obtained from all participants after being informed that the confidentiality of their results will be kept along the whole study, and thereafter.

\section{Methodology}

All patients were subjected to complete clinical and neurologic assessment. CSF oligoclonal bands $(n=9)$ and autoimmune profile $(n=15)$ (included anti-double-stranded DNA, antiphospholipid antibodies, and ANA profile) were done when needed to confirm the diagnosis of MS and exclude other autoimmune diseases. Expanded Disability Status Scale (EDSS) [11] was used to assess neurological disability among patients. Patients were categorized according to the severity of their disease into mild (EDSS 0-3), moderate (EDSS 3.5-5.5), and severe (EDSS $\geq 6$ ) [12].

\section{4-bp Del/Ins gene polymorphism genetic testing}

Patients and control groups were subjected to genetic assessment (14-bp Ins/Del gene polymorphism). Genomic DNA was brought out from blood by the method of salting. 14-bp Ins/Del genotyping was done by polymerase chain reaction (PCR) as described [13]. DNA was expanded and amplified with a set of primers: $5^{\prime}$ GTG ATG GGC TGT TTA AAG TGT CAC C-3', 5' GGA AGG AAT GCA GTT CAG CAT GA-3'. The 35 cycles of PCR were done at $94^{\circ} \mathrm{C}$ for $30 \mathrm{~s}, 64^{\circ} \mathrm{C}$ for $60 \mathrm{~s}$, and $72^{\circ} \mathrm{C}$ for $60 \mathrm{~s}$ and final cycle of $72^{\circ} \mathrm{C}$ for $10 \mathrm{~min}$. Electrophoresis of DNA segments was on $3 \%$ agarose gels containing ethidium bromide. The insertion allele was seen as a 127-bp band, while the deletion allele was visualized as 114-bp bands. The PCR was done as follows: $200 \mathrm{ng}$ of genomic DNA was added to a final volume of $25 \mu \mathrm{l}$, with final concentrations as follows: PCR buffer $1 \times, 2.0 \mathrm{mM} \mathrm{MgCl}_{2}, 0.2 \mathrm{mM}$ of each dNTP, $1.0 \mathrm{U}$ of Taq-polymerase, and $10 \mathrm{pmol}$ of each primer. Statistical analysis was performed by SPSS 18.0 software (SPSS, Inc., Chicago, IL). Quantitative data was represented as mean, standard deviation. The normality of the variables was checked using the Kolmogorov-Smirnov test. Accordingly, nonparametric tests (Mann-Whitney $U$ test) were used to compare mean between the two categorical groups and the Kruskal-Wallis test was used to compare mean between the three or more groups when datasets were found to be not normally distributed. Correlations were assessed by the Spearman rank correlation coefficient. Statistical significance was assumed at the $P$ value that was less than 0.05 .

\section{Results}

The clinical manifestations of the initial presentation of MS patients are illustrated in Table 1. The clinical 
Table 1 Clinical manifestations of initial presentation of MS patients. $n, \%$

\begin{tabular}{|c|c|c|}
\hline & Number & Percentag \\
\hline \multicolumn{3}{|l|}{ Motor manifestations } \\
\hline Hemiparesis & 15 & $31.2 \%$ \\
\hline Monoparesis & 2 & $4.2 \%$ \\
\hline Paraparesis & 5 & $10.4 \%$ \\
\hline Quadriparesis & 1 & $2.1 \%$ \\
\hline Cerebellar ataxia & 8 & $16.7 \%$ \\
\hline Total & 31 & $64.6 \%$ \\
\hline \multicolumn{3}{|l|}{ Visual manifestations } \\
\hline Optic neuritis & 10 & $20.8 \%$ \\
\hline \multicolumn{3}{|l|}{ Sensory manifestations } \\
\hline Superficial sensory impairment & 1 & $2.1 \%$ \\
\hline Deep sensory impairment & 3 & $6.2 \%$ \\
\hline Total & 4 & $8.3 \%$ \\
\hline \multicolumn{3}{|l|}{ Brain stem symptoms } \\
\hline Trigeminal neuralgia & 1 & $2.1 \%$ \\
\hline Diplopia (INO) & 2 & $4.2 \%$ \\
\hline Total & 3 & $6.3 \%$ \\
\hline \multicolumn{3}{|l|}{ Multiple symptoms at onset } \\
\hline Optic neuritis with weakness & 5 & $10.4 \%$ \\
\hline Diplopia (INO) with weakness & 1 & $2.1 \%$ \\
\hline Total $^{*}$ & 6 & $12.5 \%$ \\
\hline \multicolumn{3}{|l|}{ Recovery after first insult } \\
\hline Complete & 14 & $29.2 \%$ \\
\hline Incomplete & 31 & $64.6 \%$ \\
\hline No recovery & 3 & $6.3 \%$ \\
\hline
\end{tabular}

INO internuclear ophthalmoplegia. * $12.5 \%(n=6 / 48)$ of patients presented with more than one symptom at onset: five patients presented with optic neuritis and hemiparesis and one patient presented with diplopia due to internuclear ophthalmoplegia and monoparesis

manifestations of MS patients along MS course are illustrated in Table 2.

There was no statistically significant difference in the genotypic and allelic frequencies of HLA-G 14-bp INS/DEL polymorphism between MS patients and controls. INS/INS was the most frequently encountered genotype in both MS patients and controls $(62.5 \%$ and $70 \%$, respectively) and the difference was statistically insignificant. The alleles having 14-bp insertion had higher frequencies $(79 \%$ and $85 \%$ frequency for MS patients and controls, respectively) than deletion alleles $(20.8 \%$ in patients and $15 \%$ in controls), and the difference was statistically insignificant (Table 3). There was no statistically significant relation between14-bp insertion/deletion polymorphism genotype and either different MS clinical phenotypes or disability scores (Table 4).
Table 2 Clinical manifestations of MS patients along MS course

\begin{tabular}{|c|c|c|}
\hline & Number & Percentage \\
\hline \multicolumn{3}{|l|}{ Ocular manifestations } \\
\hline \multicolumn{3}{|l|}{ Optic neuritis } \\
\hline Diminution of vision & 19 & $39 \%$ \\
\hline Field defects & 12 & $25 \%$ \\
\hline Abnormal color vision & 2 & $4.1 \%$ \\
\hline Total & 33 & $68.1 \%$ \\
\hline \multicolumn{3}{|l|}{ Ocular motor } \\
\hline Nystagmus & 11 & $22.9 \%$ \\
\hline Internuclear ophthalmoplegia & 7 & $14.5 \%$ \\
\hline Ocular flutter & 3 & $6.25 \%$ \\
\hline Abducens palsy & 2 & $4.16 \%$ \\
\hline Total & 23 & $47.9 \%$ \\
\hline \multicolumn{3}{|l|}{ Motor manifestations } \\
\hline Hemiparesis & 20 & $41.7 \%$ \\
\hline Monoparesis & 4 & $8.3 \%$ \\
\hline Paraparesis & 5 & $10.4 \%$ \\
\hline Quadriparesis & 5 & $10.4 \%$ \\
\hline Ataxia & 12 & $25 \%$ \\
\hline Total & 46 & $95.8 \%$ \\
\hline \multicolumn{3}{|l|}{ Other cranial nerve manifestations } \\
\hline Trigeminal neuralgia & 3 & $6.25 \%$ \\
\hline Isolated facial upper motor & 2 & $4.16 \%$ \\
\hline Pseudoulbar palsy & 1 & $2.1 \%$ \\
\hline Total & 6 & $12.5 \%$ \\
\hline \multicolumn{3}{|l|}{ Sensory manifestations } \\
\hline Superficial sensory impairment & 21 & $43.8 \%$ \\
\hline Deep sensory impairment & 22 & $45.8 \%$ \\
\hline Total & 43 & $89.6 \%$ \\
\hline \multicolumn{3}{|l|}{ Neurogenic bladder manifestations } \\
\hline Precipitancy, urgency & 19 & $39.6 \%$ \\
\hline Incontinence & 4 & $8.3 \%$ \\
\hline Total & 23 & $47.9 \%$ \\
\hline Fatigue & 38 & $79.2 \%$ \\
\hline Spasticity & 8 & $16.7 \%$ \\
\hline Tonic spasms & 22 & $45.8 \%$ \\
\hline \multicolumn{3}{|l|}{ Ambulation } \\
\hline Ambulant & 32 & $66.7 \%$ \\
\hline Assisted walk & 10 & $20.8 \%$ \\
\hline Wheelchair bound & 6 & $12.5 \%$ \\
\hline
\end{tabular}

\section{Discussion}

The clinical presentation of MS has a wide range of variability which makes it more difficult to reach a confident clinical diagnosis. In the current study, as regards the clinical presentation of MS, the most frequent 
Table 3 Comparison of allelic and genotypic frequencies of 14bp insertion/deletion polymorphism of HLA-G gene between MS patients and control groups

\begin{tabular}{llll}
\hline & Case $(\boldsymbol{n}=\mathbf{4 8})$ & Control $(\boldsymbol{n}=\mathbf{5 0})$ & $\boldsymbol{P}$ value \\
\hline Genotype & & & \\
14-bp INS/INS & $30 / 48(62.5 \%)$ & $35 / 50(70 \%)$ & 0.305 \\
14-bp INS/DEL & $16 / 48(33.3 \%)$ & $15 / 50(30 \%)$ & \\
14-bp DEL/DEL & $2 / 48(4.2 \%)$ & $0 / 50(0.0 \%)$ & \\
Allele & & & \\
14-bp INS & $76(79.2 \%)$ & $85(85 \%)$ & 0.283 \\
14-bp DEL & $20(20.8 \%)$ & $15(15 \%)$ & \\
\hline
\end{tabular}

14-bp INS/DEL 14-base pair insertion/deletion, (\%) percentage of genotype in each group

presenting symptoms overall were motor symptoms (64.6\%) (Table 1). This was consistent with studies carried out in KSA (61.8\%) [14], Jordan (30.8\%) [15], and Dubai (72.8\%) [16] where motor symptoms were the most frequently encountered presenting symptoms of MS patients. In partial agreement with our findings in Iran, it was found that motor manifestations followed by sensory and then visual symptoms was the order of frequently presenting MS manifestations [17]. On the other hand, sensory impairment was the most frequent presenting symptom in Kuwait (49.2\%) and Qatar (33.3\%) [18, 19]. On the contrary, an earlier study in India found that visual symptoms (58\%) were more frequent than motor symptoms among Indian MS patients [20].
The proportion of patients with no $(6.3 \%)$ or incomplete $(64.6 \%)$ recovery from the first insult (Table 1 ) was higher than that reported in Europe among French patients (17\%) [21]. Higher levels of no or incomplete recovery after the first relapse among our patients may be attributed to the lack of awareness of MS symptoms and consequent delay in diagnosis and delay in treatment.

Fatigue is one of the main causes of impaired quality of life among MS patients [22]. Fatigue is also among the most common symptoms, reported by at least $75 \%$ of MS patients at some point in the disease course [23]. Similarly, $79.2 \%$ of patients in the present study reported a subjective sense of fatigue along the course of disease (Table 2). Although bladder manifestations are one of the most well-known symptoms of MS, with more than $90 \%$ of patients with MS experiencing bladder symptoms 10 years after disease onset [24], in the current study, only $47.9 \%$ of the sample had bladder symptoms (Table 2). This low rate might be explained by the variable duration of illness among MS patients (the mean duration of MS in our study was $5.2 \pm 4.8$ years with a range $0.5-19$ years) and low rate of spinal cord involvement in our sample $(10 / 48=20.8 \%)$ together with the partial nature of spinal cord MS pathology.

It has been reported that HLA-G polymorphism has a potential contribution to MS susceptibility [25]. Group of studies have investigated the possible relation between variable HLA-G genetic polymorphisms and MS [4, 5, 26]. HLA-G expression in MS patients is enhanced on CSF macrophages, monocytes, microglia, and endothelial cells at sites of demyelination [27]. It was reported that

Table 4 Relation of 14-bp insertion/deletion polymorphism genotype to clinical, laboratory, cognitive, and psychological assessment of MS patients

\begin{tabular}{|c|c|c|c|c|}
\hline & \multicolumn{3}{|l|}{ Genotype } & \multirow[t]{2}{*}{$P$-value } \\
\hline & 14-bp INS/INS $(n=30)$ & 14-bp INS/DEL $(n=16)$ & 14-bp DEL/DEL $(n=2)$ & \\
\hline \multicolumn{5}{|c|}{ Patients' age at presentation } \\
\hline Mean \pm SD & $32.3 \pm 8.7$ & $30.6 \pm 5.9$ & $26.5 \pm 12.0$ & 0.601 \\
\hline Range & $16-49$ & $20-41$ & $18-35$ & \\
\hline \multicolumn{5}{|c|}{ Age at MS onset years } \\
\hline Mean $\pm S D$ & $26.5 \pm 7.7$ & $25.9 \pm 6.1$ & $24.0 \pm 11.3$ & 0.412 \\
\hline Range & $14-45$ & $18-36$ & $16-32$ & \\
\hline \multicolumn{5}{|l|}{ MS duration } \\
\hline Mean \pm SD & $5.9 \pm 5.3$ & $4.2 \pm 4.1$ & $2.5 \pm 0.7$ & 0.897 \\
\hline Range & $0.5-19$ & $0.5-14$ & $2-3$ & \\
\hline \multicolumn{5}{|c|}{ Total number attacks } \\
\hline Mean $\pm S D$ & $3.3 \pm 2.5$ & $3.7 \pm 2.9$ & $2.5 \pm 0.7$ & 0.861 \\
\hline Range & $1-10$ & $1-10$ & $2-3$ & \\
\hline \multicolumn{5}{|l|}{ EDSS score } \\
\hline Mean $\pm S D$ & $4.3 \pm 2.3$ & $3.9 \pm 1.7$ & $3.0 \pm 0.0$ & 0.372 \\
\hline Range & $1-9$ & $2-7$ & $3-3$ & \\
\hline
\end{tabular}


the 14-bp DEL/ + 3142 G combined genotypic frequency was related significantly to MS risk [28]. To the best of our knowledge, there are no available data regarding this issue for Egyptian patients with MS.

The present study showed no significant difference between patients and controls regarding genotypic and allelic frequencies of 14-bp INS/DEL polymorphism reflecting an insignificant risk of this polymorphism to MS susceptibility $(P=0.305)$ (Table 3$)$. Similarly, a study from Tunisia demonstrated that there was a lack of association between the 14-bp INS/DEL polymorphism and the risk of having MS [28]. Moreover, Kroner and colleagues studied three polymorphic sites in the HLA-G genetic site including the 14-bp INS/DEL polymorphism and found no relation between any of these three polymorphisms and MS in the German population [4]. Furthermore, a meta-analysis was carried out to find the link between the 14-bp INS/DEL polymorphism and various autoimmune diseases. It concluded that this polymorphism is not linked to MS and rheumatoid arthritis, but associated with several other autoimmune diseases such as systemic lupus erythematosus and Crohn's disease. This finding suggests that this genetic polymorphism functionality is disease dependent. Thus, HLA-G 14-bp INS/DEL polymorphism is not a usual genetic factor for different autoimmune disorders but other various pathogenic mechanisms are linked to the emergence of polygenetic autoimmune disorders [29].

On the other hand, an Iranian study demonstrated that HLA-G 14-bp insertion/deletion polymorphism could be a risk factor for MS susceptibility [25].

The controversy between studies of HLA-G 14-bp INS/DEL polymorphism could be attributed to variance in sample sizes, the ethnic groups, and methods used in different studies besides variable environmental factors. This leads to a suggestion that other different HLA-G polymorphic sites may work together to affect HLA-G expression in MS.

However, Fredj and his colleagues found that 14-bp DEL/ + 3142 G haplotype combined genotype (+3142 G another studied polymorphic site) had significantly increased frequency in MS patients compared to controls [28].

Wisniewski and coauthors when evaluating the $-725 \mathrm{C}$ $>\mathrm{G}>\mathrm{T},-716 \mathrm{~T}>\mathrm{G}$, and 14-bp INS/DEL HLA-G polymorphisms in MS have found that the -725G/-716T/14bp DEL haplotype may be a susceptibility factor to this disease in the Polish population [30]. This confirms that the MS risk susceptibility may be not linked to a single allele but may depend on the combination of different polymorphic genetic sites.

The current study found no association between the 14-bp INS/DEL polymorphism genotypes and clinical characteristics or disease disability of MS patients assessed by EDSS (Table 4). Similarly, Fredj and his colleagues reported that the 14-bp INS/DEL polymorphism genotype had no effect on the initiation of the disease [28]. Furthermore, previous studies found no association between HLA-G 14-bp INS/DEL gene polymorphism and the severity of MS [4, 25, 28]. On the other hand, it has been reported that MS patients with 14-bp INS/INS and 14-bp INS/DEL genotypes are more early disease onset compared to patients with 14-bp DEL/DEL genotype [30]. However, in the current study, patients with 14-bp INS/INS and 14-bp INS/DEL genotypes tend to have a later age of MS onset (Table 4) but the difference was insignificant.

Taken together, the results of this study emphasize that the HLA-G 14-bp INS/DEL polymorphism alone does not affect MS susceptibility. This means that other polymorphic genetic sites may have an important role in the regulation of the risk of developing MS. Thus, it can be confirmed that different polymorphic sites interact to modulate the HLA-G role in MS. Therefore, a more extensive research is needed to better clarify the interactive relation between the 14-bp INS/DEL polymorphism, other HLA-G polymorphic sites, and MS. Moreover, further investigations are needed to evaluate detailed HLA$\mathrm{G}$ polymorphisms and transcription and translation rate of the HLA-G gene under different pathological and normal conditions.

\section{Conclusion}

The HLA-G 14-bp INS/DEL polymorphism alone may be not a genetic risk factor for MS, but it may be involved together with other HLA-G polymorphic sites in different pathogenic mechanisms that related to the development of polygenic autoimmune diseases like MS.

\begin{abstract}
Abbreviations
14 bp: 14 base pairs; 3'UTR: 3' untranslated region; CDMS: Clinically definite MS; CNS: Central nervous system; EDSS: Expanded Disability Status Scale; HC: Healthy controls; HLA-G: Human leukocyte antigen-G; INO: Internuclear ophthalmoplegia; INS/DEL: Insertion/deletion; MHC: Major histocompatibility complex; mRNA: Messenger ribonucleic acid; MS: Multiple sclerosis; PCR: Polymerase chain reaction; RRMS: Relapsing-remitting MS; SNP: Single nucleotide polymorphism
\end{abstract}

\section{Acknowledgements}

The authors are indebted to all patients who participated in this study. The authors are indebted to members of the Neuroepidemiology research center, Faculty of Medicine, Assiut University, for their valuable contribution in conducting the research work.

\section{Authors' contributions}

W.M.F, H.N.E, and H.M.S designed the study. H.K.E, M.A.S, H.M.E, and M.G.A collected clinical data and selected the patients. H.M.S, A.K, and A.R.A performed the sample collection, preparation, and molecular analysis. H.K.E, H.M.E, M.A.S, M.G.A, A.R.A, and A.K conducted data interpretation and statistical analysis. W.M.F, H.K.E, H.N.E, M.A.S, H.M.S, and M.G.A performed writing the research paper. All authors critically reviewed the manuscript and checked and approved the final version.

Funding

Not applicable. 


\section{Availability of data and materials}

The authors confirm that the data supporting the findings of this study are available within the article.

\section{Declarations}

Ethics approval and consent to participate

The study protocol was approved by the Ethics committee of Sohag Faculty of Medicine in November 2016 (the committee reference number is not applicable). Written informed consent was obtained from all participants after being informed that the confidentiality of their results will be kept along the whole study, and thereafter.

\section{Consent for publication}

Written informed consent was obtained from all participants.

\section{Competing interests}

The authors declare that they have no competing interests.

\section{Author details}

${ }^{1}$ Department of Neurology, Assiut University, Assiut, Egypt. ${ }^{2}$ Department of Anatomy, College of Medicine, Jouf University, Sakakah, Kingdom of Saudi Arabia. ${ }^{3}$ Histology and Cell Biology, Tissue Culture and Molecular Biology Center, Faculty of Medicine, Assiut University, Assiut, Egypt. ${ }^{4}$ Department of Neurology, Faculty of Medicine, Sohag University, Sohag, Egypt. ${ }^{5}$ Department of Clinical Pathology, Faculty of Medicine, Sohag University, Sohag, Egypt.

\section{Received: 11 September 2020 Accepted: 29 April 2021}

\section{Published online: 11 May 2021}

\section{References}

1. Ebers $G$, Sadovnick A, Risch N. A genetic basis for familial aggregation in multiple sclerosis. Nature. 1995;377(6545):150-1. https://doi.org/10.1038/3 $77150 \mathrm{a0}$.

2. Browne $P$, Chandraratna D, Angood C, Tremlett H, Baker C, Taylor BV, et al. Atlas of multiple sclerosis 2013: a growing global problem with widespread inequity. Neurology. 2014;83(11):1022-4. https://doi.org/10.1212/WNL. 0000000000000768.

3. Consortium IMSG. Risk alleles for multiple sclerosis identified by a genomewide study. N Engl J Med. 2007;357(9):851-62.

4. Kroner A, Grimm A, Johannssen K, Mäurer M, Wiendl H. The genetic influence of the nonclassical MHC molecule HLA-G on multiple sclerosis. Human Immunol. 2007;68(5):422-5. https://doi.org/10.1016/j.humimm.2007. 01.012.

5. Cree BA, et al. A major histocompatibility Class I locus contributes to multiple sclerosis susceptibility independently from HLA-DRB1* 15: 01. Plos One. 2010;5(6):e11296. https://doi.org/10.1371/journal.pone.0011296.

6. Hviid TVF, et al. HLA-G and IL-10 in serum in relation to HLA-G genotype and polymorphisms. Immunogenetics. 2004;56(3):135-41. https://doi.org/1 0.1007/s00251-004-0673-2.

7. Chen XY, Yan WH, Lin A, Xu HH, Zhang JG, Wang XX. The 14 bp deletion polymorphisms in HLA-G gene play an important role in the expression of soluble HLA-G in plasma. Tissue Antigens. 2008;72(4):335-41. https://doi. org/10.1111/j.1399-0039.2008.01107.x.

8. Svendsen SG, Hantash BM, Zhao L, Faber C, Bzorek M, Nissen MH, et al. The expression and functional activity of membrane-bound human leukocyte antigen-G1 are influenced by the 3'-untranslated region. Hum Immunol. 2013;74(7):818-27. https://doi.org/10.1016/j.humimm.2013.03.003.

9. Renoux C. Natural history of multiple sclerosis: long-term prognostic factors. Neurol Clin. 2011;29(2):293-308. https://doi.org/10.1016/j.ncl.2011.01.006.

10. Thompson AJ, Banwell BL, Barkhof F, Carroll WM, Coetzee T, Comi G, et al. Diagnosis of multiple sclerosis: 2017 revisions of the McDonald criteria. Lancet Neurol. 2018;17(2):162-73. https://doi.org/10.1016/S1474-4422(17)30470-2.

11. Kurtzke JF. Rating neurologic impairment in multiple sclerosis: an expanded disability status scale (EDSS). Neurology. 1983;33(11):1444-52. https://doi. org/10.1212NNL.33.11.1444.

12. Harandi AA, Shahbeigi S, Pakdaman H, Fereshtehnejad SM, Nikravesh E, Jalilzadeh R. Association of serum $25(\mathrm{OH})$ vitamin D3 concentration with severity of multiple sclerosis. Iran J Neurol. 2012;11(2):54-8.
13. Consiglio C, et al. Association of the HLA-G gene+ $3142 \mathrm{C}>\mathrm{G}$ polymorphism with systemic lupus erythematosus. Tissue Antigens. 2011;77(6):540-5. https://doi.org/10.1111/j.1399-0039.2011.01635.x.

14. Daif A, al-Rajeh S, Awada A, al Bunyan M, Ogunniyi A, AbdulJabar M, et al. Pattern of presentation of multiple sclerosis in Saudi Arabia: analysis based on clinical and paraclinical features. Eur Neurol. 1998;39(3):182-6. https://doi. org/10.1159/000007931.

15. El-Salem K, et al. Multiple sclerosis in Jordan: a clinical and epidemiological study. J Neurol. 2006;253(9):1210-6. https://doi.org/10.1007/s00415-006-0203-2.

16. Inshasi J, Thakre M. Prevalence of multiple sclerosis in Dubai, United Arab Emirates. Inte J Neurosci. 2011;121(7):393-8. https://doi.org/10.3109/002074 54.2011.565893.

17. Kalanie H, Gharagozli K, Kalanie AR. Multiple sclerosis: report on 200 cases from Iran. Multiple Scler J. 2003;9(1):36-8. https://doi.org/10.1191/13524 $58503 \mathrm{~ms} 8870 a$

18. Alroughani R, Ashkanani A, Lamdhade S. Clinical characteristics of multiple sclerosis in Kuwait: data from the new MS registry of Amiri Hospital. Int J Neurosci. 2012;122(2):82-7. https://doi.org/10.3109/00207454.2011.630543.

19. Deleu D, Mir D, al Tabouki A, Mesraoua R, Mesraoua B, Akhtar N, et al. Prevalence, demographics and clinical characteristics of multiple sclerosis in Qatar. Mult Scler J. 2013;19(6):816-9. https://doi.org/10.1177/1352458512459291.

20. Jain S, Maheshwari M. Multiple sclerosis: Indian experience in the last thirty years. Neuroepidemiology. 1985;4(2):96-107. https://doi.org/10.1159/000110220.

21. Confavreux C, Vukusic S. Natural history of multiple sclerosis: a unifying concept. Brain. 2006;129(3):606-16. https://doi.org/10.1093/brain/awl007.

22. Krupp LB, Alvarez LA, LaRocca NG, Scheinberg LC. Fatigue in multiple sclerosis. Arch Neurol. 1988;45(4):435-7. https://doi.org/10.1001/archneur.1 988.00520280085020.

23. Lerdal A, Gulowsen Celius E, Krupp L, Dahl AA. A prospective study of patterns of fatigue in multiple sclerosis. Eur J Neurol. 2007;14(12):1338-43. https://doi.org/10.1111/j.1468-1331.2007.01974.x.

24. Khalaf KM, Coyne KS, Globe DR, Armstrong EP, Malone DC, Burks J. Lower urinary tract symptom prevalence and management among patients with multiple sclerosis. Int J MS Care. 2015;17(1):14-25. https://doi.org/10.7224/1 537-2073.2013-040.

25. Mohammadi N, Adib M, Alsahebfosoul F, Kazemi M, Etemadifar M. An investigation into the association between HLA-G 14 bp insertion/deletion polymorphism and multiple sclerosis susceptibility. J Neuroimmunol. 2016; 290:115-8. https://doi.org/10.1016/j.jneuroim.2015.11.019.

26. Rizzo R, Bortolotti D, Fredj NB, Rotola A, Cura F, Castellazzi M, et al. Role of HLA$\mathrm{G} 14 \mathrm{bp}$ deletion/insertion and $+3142 \mathrm{C}>\mathrm{G}$ polymorphisms in the production of sHLA-G molecules in relapsing-remitting multiple sclerosis. Hum Immunol. 2012;73(11):1140-6. https://doi.org/10.1016/j.humimm.2012.08.005.

27. Wiendl H, Feger U, Mittelbronn M, Jack C, Schreiner B, Stadelmann C, et al. Expression of the immune-tolerogenic major histocompatibility molecule HLA-G in multiple sclerosis: implications for CNS immunity. Brain. 2005; 128(11):2689-704. https://doi.org/10.1093/brain/awh609.

28. Fredj NB, et al. The association between functional HLA-G 14 bp insertion/ deletion and +3142 C> G polymorphisms and susceptibility to multiple sclerosis. Immunol Lett. 2016;180:24-30. https://doi.org/10.1016/j.imlet.201 6.10.006.

29. Lee YH, Bae SC. Association between a functional HLA-G 14-bp insertion/ deletion polymorphism and susceptibility to autoimmune diseases: a metaanalysis. Cell Mol Biol (Noisy-le-grand). 2015;61(8):24-30.

30. Wiśniewski A, Bilińska M, Klimczak A, Wagner M, Majorczyk E, Nowak I, et al. Association of the HLA-G gene polymorphism with multiple sclerosis in a Polish population. Int J Immunogenet. 2010;37(4):307-11. https://doi.org/1 0.1111/j.1744-313X.2010.00926.x.

\section{Publisher's Note}

Springer Nature remains neutral with regard to jurisdictional claims in published maps and institutional affiliations. 